\title{
Assessment of Health Care Delivery and Patients' Satisfaction at Obuasi Government Hospital in the Ashanti Region of Ghana
}

\author{
Sylvia Ahinee Adjedu \\ Community Health Nurses Training College-Tanoso, Post Office Box 2066, Tanoso, Ghana
}

\begin{abstract}
Quality Health care is a global issue and people's health is an essential to human development and improvement of their economies. The aim of this research study was to assess health care delivery and patients' satisfaction at Obuasi Government Hospital in the Ashanti Region of Ghana. The research used a cross-sectional descriptive study. Purposive and simple random sampling techniques were used to select the respondents at the OPD. The total sample size for the study was 50 respondents. The data collection tool employed in this study was structured interview guide. From the study findings, 39 (78\%) indicated yes, they knew the patient's charter whereas $11(22 \%)$ indicated no. Majority of the respondents $41(82 \%)$ of the respondents were dissatisfied about the time spent at the hospital while $9(18 \%)$ of the respondents were satisfied and relating to the general assessment of services received by the respondents, more than half of the respondents, $28(56 \%)$ of the respondents were satisfied while $22(44 \%)$ of the respondents were dissatisfied. The study recommended that the implementation of the Health Information Management System will help reduce patient waiting time and complaints unit should be instituted to enable patients report the performance of the hospital and adequate physicians and health staff at the hospital should be increased.
\end{abstract}

Keywords: Quality care, Patients' rights, health delivery, Patients' satisfaction, healthcare

DOI: $10.7176 / \mathrm{JHMN} / 79-01$

Publication date:August $31^{\text {st }} 2020$

\section{Background}

Accessible and quality health care is now a global concern. World Health Organisation (2012) notes that research findings in developed countries on quality healthcare delivery have gradually influenced developing nations in the assessment of their quality healthcare systems. Outcomes have received special prominence as a measure of quality healthcare (WHO, 2012). Good health is indispensable and essential to the human development as well as improving global economy (Brundtland, 2001). Accessible and efficient health delivery system compelled the adoption of various human rights provision at the national and international level to protect and enhance basic needs of human kind including the right to adequate and quality health care during sickness. For instance, Article 25 of the UN Declaration of Human Rights stipulate s that "Everyone has the right to a standard of living adequate for the health and well-being of himself and his family, including food, clothing, housing, medical care, and necessary social services" (Ovretveit, 2001).

It is argued that health service delivery is a required input to population health status, coupled with other factors, including social determinants of health. Nevertheless, the content of health services differ from one country to another, thus in any well-functioning health system, the network of service delivery and provision is based on comprehensiveness, accessibility, continuity, co-ordination and efficiency (WHO, 2016). Likewise, Howard (2000) argues that health care sector is experiencing an express transformation to meet the ever-increasing needs and demands of the patient's population. It has been established that to move towards higher quality health care delivery, more and better information is usually required on existing provision, on the interventions offered and on major constraints on service implementation (WHO, 2000).

Matters concerning responsiveness in health care delivery systems are many and varied. One fundamental distinction is between elements related to respect for human beings as persons, who are basically subjective and judged mainly by the patients and objective elements connected to how a system meets common expressed concerns of patients and their families as clients of health systems. Observations on these things are done at the various health facilities (WHO, 2000). Respect for persons thus include: 1) respect for the dignity of the person; 2) confidentiality or the right to determine who has access to one's personal health information; 3) autonomy to participate in choices about one's own health including helping patients to choose what treatment to receive or not (Ghana Health Service Patients' Rights Charter, 2008).

Patients prefer safe, appropriate interventions, treatment, and care that ensures their dignity and respect. They need services in accurate, timely, and appropriate manner. It is noted that to attain quality health care services, then consumers of health services must be engaged and consulted always, not only in relation to their own healthcare, but also about service planning and delivery, health evaluation and research (Graham, 2001). It is argued that patients' satisfaction offer healthcare managers with valuable information about the structures, process, and outcomes of care. This has created the need for a system of continuous quality improvement aimed at providing valued services to the consumer. 
Patient's perception about healthcare has been predominantly accepted as an important indicator for measuring quality of health care and a critical component of performance improvement and clinical effectiveness (Fekadu, 2011). Various dimensions of patient satisfaction have been identified, ranging from admission to discharge services, as well as from medical care to interpersonal communication. It is suggested that well recognized criteria include responsiveness, communication, attitude, clinical skill, comforting skill, amenities and food services (Bell, Krivich, and Boyd, 1997). Despite all the efforts by the Ghana's Ministry of Health, Ghana Health Service, donor funding agencies and other stakeholders to improve quality health care delivery in Ghana, there is still perceived unsatisfactory services rendered by the staff of hospitals in areas of care and treatment, relationship between patients and care givers, patients' consent and confidentiality, sanitation of working environment, access to basic information about their rights, consent and confidentiality of patients, among others (Leatherman \& Sutherland, 2003).

Although some research has been carried out on patient's satisfaction, there have been few empirical investigations into patient's satisfaction pertaining to outpatients' clinical services in Ghana. It is in the light of this that this study assesses health care delivery and patients' satisfaction at Obuasi Government Hospital to help address research gap.

\section{Methods}

\section{Study design and setting}

This research adopted a cross-sectional descriptive study assess health care delivery and patients' satisfaction at Obuasi Government Hospital. Cross-sectional research study is constructed on explanations that take place in diverse groups at one period. This means there was no experimental system, so no variables were influenced by the researcher. The study purposefully centred on patients at the Out-Patient Department (OPD) who were sick people from all walks of life with diverse professional, educational, religious and ethnic backgrounds. Since these facilities are all institutional-based, there was the possibility of capturing responses from students and staff accessing healthcare.

\section{Sampling Technique and Sample Size}

Purposive and Simple random sampling techniques were used to select the respondents at the OPD. Purposive sampling method demonstrates to be effective the because of the limited numbers of people serving as primary data sources due to the nature of research design and study objectives. The simple random method ensures that each respondent is chosen entirely by chance and each member of the population has an equal chance of being included in the sample to avoid bias. The total sample size for the study was 50 respondents at the OPD. This sample size for the population-based survey was determined largely due to the average OPD attendance rate and this made the sample very representative.

\section{Data Collection Tools}

The data collection tool employed in this study was structured interview guide. The interview guide was given to the respondents at the OPD and the researcher helped the respondents to complete the data collection tool. The interview guide is one of the best ways of collecting data from respondents who may have no or limited education to obtain an in-depth response from such respondents. Sessions of the interview guide consisted of five points Likert scale items, with 1 and 5 indicating the lowest and highest levels of satisfaction, respectively. Patients indicated their level of satisfaction by selecting responses ranging from very dissatisfied $=1$, dissatisfied $=2$, Satisfied $=3$ and very satisfied $=4$.

\section{Ethical Consideration}

Before the onset of data collection, ethical clearance was sought from the Municipal Director of Health Services (Obuasi Municipal Health Directorate). The medical superintendent of Obuasi Municipal Government Hospital and head of the OPD. Informed verbal consent was sought from respondents before they were involved in the study and their responses were only used only for the purpose of this research and information that respondents offered were kept confidentially.

\section{Results}

\section{Demographic Characteristics of Respondents}

In relation to the gender of the respondents, $32(64 \%)$ of the respondents were females whereas $18(36 \%)$ were males. Concerning the respondents' age, those who were within the age range of 36 to 45 were $14(28 \%)$, respondents who ages fell within the range of 46-55 were 12 (24\%), and those within the ages of 26-35 years were $11(22 \%)$ while those within below 25 years were $6(12 \%)$. About the respondents' marital status, majority of the respondents, $32(64 \%)$ were married, respondents who were single formed 14 (28\%) while those within the category of divorced were $4(8 \%)$. In connection with the educational qualification of the respondents, those with 
basic education were $20(40 \%)$, respondents who possessed secondary education were $19(38 \%)$ whereas $11(22 \%)$ of the respondents had tertiary qualifications. Concerning the religious affiliation of the respondents, 35 constituting 70\% were Christians while 15 (30\%) were Moslems.

\section{Level of Awareness of Patient on Patient's Charter Promulgated to protect their Right}

This study objective intended to assess the level of awareness of patients on patient's charter promulgated to protect their rights. The results show that 39 (78\%) indicated yes, they knew the patient's charter whereas $11(22 \%)$ indicated no knowledge about the patient charter. To confirm the respondents' knowledge, they were asked to mention some of the component of the patient charter and all the $39(78 \%)$ of the respondents were able to mention some of the components. Concerning the question on the respondents possessing knowledge to report any misconduct and unsatisfactory service from any hospital staff, almost all the respondents 46 (92\%) indicated yes that have the requisite knowledge to report any misconduct while only $4(8 \%)$ in no to the question.

\section{Patients' satisfaction with the Services they receive from their Health Provider}

The respondents were asked questions to ascertain whether patients are satisfied with the services they receive from their health provider. In relation to human relations of the staff at the hospital, $40(80)$ of the respondents were satisfied with whereas $10(20 \%)$ of the respondents were dissatisfied. About staff communication at the hospital, $41(82 \%)$ of the respondents were satisfied whiles $9(18 \%)$ of the respondents were dissatisfied. Concerning the question on staff' attitude towards patients at the hospital, 39 (78\%) of the respondents were satisfied whereas the $11(22 \%)$ of them were dissatisfied.

In connection with the patients' satisfaction with the time spent at the hospital, majority of the respondents $41(82 \%)$ of the respondents were dissatisfied about the time spent at the hospital while $9(18 \%)$ of the respondents were satisfied. Relating to the general assessment of services received by the respondents, more than half of the respondents, $28(56 \%)$ of the respondents were satisfied while $22(44 \%)$ of the respondents were dissatisfied. Recommending the hospital to other patients, $35(70 \%)$ of the respondents indicated satisfied and $15(30 \%)$ of the respondents indicated dissatisfied when recommending the hospital to others.

Table 1: Level of patients' satisfaction

\begin{tabular}{llll}
\hline Variable & $\begin{array}{l}\mathrm{N}=50 \\
\text { Satisfactory }\end{array}$ & Unsatisfactory & Total \\
\hline Staff human relations & $40(80)$ & $10(20)$ & $(100)$ \\
Staff's Communication & $41(82)$ & $9(18)$ & $11(22)$ \\
Attitude of staff & $39(78)$ & $41(82)$ & $(100)$ \\
Satisfaction with the time spent & $9(18)$ & $22(44)$ \\
General assessment of services & $28(56)$ & $15(30)$ & $(100)$ \\
Recommending the hospital & $35(70)$ &
\end{tabular}

The figures in parentheses are the percentages

Source: Field Survey, 2019 
Patients' Satisfaction of Services and the Awareness of their Rights and how they Influence Each Other

The respondents answered several questions in relation to the relationships that exist between patients' satisfaction of services and the awareness of their rights and how they influence each other, and Table 8 presents some of the responses provided by the respondents.

Table 2: Patients' Awareness on Patient Charter

\begin{tabular}{llc}
\hline Variable & $\begin{array}{l}\mathrm{N}=50 \\
\text { Frequency }\end{array}$ & Percentage \\
\hline Quality services by Law & 48 & 96 \\
Yes & 2 & 4 \\
No & 49 & 98 \\
Demand of quality care & 1 & 2 \\
Yes & & \\
No & 44 & 88 \\
Reporting misconduct & 6 & 12 \\
Yes & & \\
No & 30 & 60 \\
Availability of channels & 20 & 40 \\
Yes &
\end{tabular}

Source: Field Survey, 2019

The respondents were asked if they were entitled to quality services by law, almost all the respondents comprising $48(96 \%)$ of the respondents indicated yes while $2(4 \%)$ of the respondents indicated no. About the question on the respondents' knowledge on patient charter helped them to receive quality health care services, 49 $(98 \%)$ of the respondents indicated yes whereas $1(2 \%)$ indicated no. About whether the respondents were well informed to report any misconduct and unsatisfactory services provided to them to the appropriate authorities, 45 $(90 \%)$ of the respondents marked yes and $5(10 \%)$ of the respondents marked no to the question. Relating to the question on the availability of visible channels at the hospital through which patients can report their dissatisfaction about services, $30(60 \%)$ of the respondents indicated yes while $20(40 \%)$ of the respondents indicated no. Respondents were asked to offer suggestions that will enhance patients' satisfaction at Obuasi Government Hospital.

\subsection{Discussion}

Regarding the gender of the respondents, $32(64 \%)$ of the respondents were females whereas $18(36 \%)$ were males. In connection with the educational qualification of the respondents, those with basic education were $20(40 \%)$, respondents who possessed secondary education were $19(38 \%)$ whereas $11(22 \%)$ of the respondents had tertiary qualifications. The respondents who have on the patient charter and could mention some of the component of the patient charter were $39(78 \%)$ of the respondents. Again, almost all the respondents $46(92 \%)$ indicated yes that have the requisite knowledge to report any misconduct while only $4(8 \%)$ in no to the question.

Therefore, it could be argued that educated individuals will seek patient satisfaction at the hospital which is grounded as part of health outcome quality, which encompasses the clinical results, economic measures and health related quality of life. These days health education offered to the general public particularly those in the remote and deprived areas is enabling persons becoming aware of their right to quality service delivery as far as their health is concerned (Sitzia \& Wood, 2002).

In relation to human relations of the staff at the hospital, $40(80)$ of the respondents were satisfied with whereas $10(20 \%)$ of the respondents were dissatisfied and about staff communication at the hospital, 41 (82\%) of the respondents were satisfied whiles $9(18 \%)$ of the respondents were dissatisfied. The above finding supports Ghana Health Service Report (2002) concluding that with the requisite laws in place, availability of qualified health workers, with the right tools and willing to work according to the laws and patients ready and willing to take up their responsibilities, the health system should be able to provide a satisfactory service to the patients. In connection with the patients' satisfaction with the time spent at the hospital, majority of the respondents $41(82 \%)$ of the respondents were dissatisfied about the time spent at the hospital while $9(18 \%)$ of the respondents were satisfied. These study findings corroborate Pakdil \& Harwood (2005) suggestions that patients' satisfactions by measuring the discrepancy between patients' expectations and perceptions established that patients are highly satisfied with all elements of service quality in timely manner; precision, satisfactory information about their operation and suitable friendliness and courtesy elements.

Recommending the hospital to other patients, $35(70 \%)$ of the respondents indicated satisfied in terms of recommending the health facility to others and $15(30 \%)$ of the respondents indicated dissatisfied when recommending the hospital to others claiming that the hospital needs additional health facilities and staff. It can be explained that quality service delivery leads to patient satisfaction and Clients' satisfaction can lead to high 
customer loyalty and recommending that satisfactory services to others.

Almost all the respondents comprising $48(96 \%)$ of the respondents indicated that they were entitled to quality services by law while $2(4 \%)$ of the respondents indicated the contrary. These results could be explained when clients rights are respected by others, especially health care providers, they will be more satisfied and secured. In terms of ascertaining wheather the respondents knowledge on Ghana's patient charter has influenced them to receive quality health care services, 49 (98\%) of the respondents stated that the patient charter had an influence whereas 1 respondents disagreeing. Interestingly, today's clients are informed and also sensitive to poor services which make them reluctant to return for services when they perceive quality to be poor. Therefore, the quality of service will remain a key success factor in the component of the healthcare delivery in hospitals especially in Ghana. Relating to the question on the availability of visible channels at the hospital through which patients can report their dissatisfaction about services, $30(60 \%)$ of the respondents indicated yes while $20(40 \%)$ of the respondents indicated no. Probably, this could be explained that Ghana's health system has undergone several developments over the years with the utmost target of creating outstanding improvements in healthcare delivery.

\section{Limitations}

Only the OPD was used for the study and this is notably very small. The study was limited in terms of extrapolating the findings for the entire Obuasi Municipal Hospital as more departments should have be chosen for the study, but time constraint did not permit this. The OPD was selected for the study which was not very representative of the entire hospital. The time allocated for the research was very limited coupled with respondents not willing to involve themselves in the research because of their health condition.

\section{Conclusion}

The study findings on assessing health care delivery and patients' satisfaction at Obuasi Government Hospital could be concluded that the residents than half of the respondents, $28(56 \%)$ of the respondents were satisfied with the health care services they received and there is the need for the hospital to improve upon their services. From the study findings, majority of the respondents were dissatisfied with the time spent the hospital and majority of the respondents always also the patient charter. The findings of the study suggest that to reduce the service delivery time, there is the need for the hospital to improve efficiency of services to reduce the waiting time in accessing health care. In the absence of adequate physicians at the hospital, the hospital should assign more health professionals in peak periods or days to enable them to cater for patients and periodic patient satisfaction survey should be institutionalized to provide feedback for continuous quality improvement.

\section{REFERENCES}

Atinga, R.A., Abekah-Nkrumah, G. \& Domfeh, K.A. (2011). Managing healthcare quality: a necessity of patient satisfaction. International Journal of Healthcare Quality Assurance, 24 (7), 548-563.

Bell, R., Krivich, M. J. and Boyd, M. S. (1997). Charting patient satisfaction. Marketing Health Services, vol. 17 (2), p. $22-30$

Brundtland G. H. (2001). Improving health systems' performance. $O E C D$, p. 4

Curry, A., \& Sinclair, E. (2002). Assessing the quality of physiotherapy services using SERVQUAL. International Journal of Health Care Quality Assurance, 15(5), 197-205.

Fekadu, A., Andualem M, \& Yohannes, H. M. (2011). Assessment of clients' satisfaction with health service delivery At Jimma Unversity Specialized Hospital. Ethopian Journal of Health Sciences, 21(2), 101-109.

Graham J. D. (2001). Quality healthcare: what consumers want? OECD, p.32

Ghana Health Service (2008). The Patient's Charter, Ghana Health Service, Accra, Ghana.

Howard, J.E. (2000), Customer service: The key to remaining competitive in managed care. Quartely, vol. 8 (2), p. $22-29$

Kravitz R. L. (1996). Patients' Expectations for Medical Care: An Expanded Formulation Based on Review of the Literature. Medical Care Research and Review, vol. 53, p. 3-27.

Leatherman, S., \& Sutherland, K. (2003). The quest for quality in the NHS: A midterm evaluation of the ten-year quality agenda. The Stationery Office.

Ovretveit, J. (2001). The Norwegian approach to integrated quality development. Journal of Management in Medicine, vol. 15 (2), p.125-132.

Pakdil, F., \& Harwood, T.M. (2005). Patient satisfaction in a pre-operative assessment clinic: an analysis using SERVQUAL dimensions. Total Quality Management, 16(3),15- 30.

Sitzia, J. and Wood, N. (2002). Response rate in patient satisfaction research: an analysis of 210 published studies. Int J Qual Health Care 1998; 10:311-17. International Journal for Quality in Health Care, vol. 14 (5), p. 353 $-358$

Williams, J. and Calnan , M. (1991). Convergence \& divergence: assessing criteria of consumer satisfaction across general practice, dental \& hospital care settings. Social Science \& Medicine. 33: 707-716

World Health Organisation (2000). Health systems: improving performance. World Health Organization. 
World Health Organization (2008). Healthcare quality measures-Statewide quality report. Geneva: World Health Organization.

World Health Organization (2012). Patient Safety Research a guide for developing training programmes. Geneva: World Health Organization

World Health Organization (2016). Quality of care: a process for making strategic choices in health systems. Geneva: World Health Organization.

World Health Organization (2014). Ten facts on Patients Safety. Geneva: World Health Organization. 